\title{
Mechanical durability of hydrophobic surfaces fabricated by injection moulding of laser-induced textures
}

Jean-Michel Romano $\left(1,{ }^{*}\right)$, Mert Gulcur (2), Antonio Garcia-Giron (1), Elena Martinez-Solanas $(3,4)$, Ben R. Whiteside (2), Stefan S. Dimov (1)

(1) School of Mechanical Engineering, University of Birmingham, Edgbaston, Birmingham B15 2TT, $U K$

(2) Centre for Polymer Micro \& Nano Technology, Faculty of Engineering and Informatics, School of Engineering, University of Bradford, Bradford BD7 1DJ, UK

(3) ATRIA Innovation, C/Alaún 14, nave 5, 50197, Zaragoza, Spain

(4) BSH Home Appliances, Av. de la Industria 49, 50016 Zaragoza, Spain

*J.Romano@bham.ac.uk 


\section{ABSTRACT.}

The paper reports an investigation on the mechanical durability of textured thermoplastic surfaces together with their respective wetting properties. A range of laser-induced topographies with different aspect ratios from micro to nanoscale were fabricated on tool steel inserts using an ultrashort pulsed near infrared laser. Then, through micro-injection moulding the topographies were replicated onto polypropylene surfaces and their durability was studied systematically. In particular, the evolution of topographies on textured thermoplastic surfaces together with their wetting properties were investigated after undergoing a controlled mechanical abrasion, i.e. reciprocating dry and wet cleaning cycles. The obtained empirical data was used both to study the effects of cleaning cycles and also to identify cleaning procedures with a minimal impact on textured thermoplastic surfaces and their respective wetting properties. In addition, the use of 3D areal parameters that are standardised and could be obtained readily with any state-of-the-art surface characterisation system are discussed for monitoring the surfaces' functional response.

Keywords: laser texturing, injection moulding, wettability, cleaning, durability, areal parameters. 


\section{Introduction}

The design and manufacture of thermoplastic surfaces with tailored wettability is of increasing interest. While good wettability is important for many fields, e.g. coating and adhesion[1], the opposite effect is sought in producing easy-to-clean surfaces[2,3]. Such surfaces exhibit low surface energy and repel liquids. The thermodynamic equilibrium of a liquid (L) wetting a solid surface $(\mathrm{S})$ is given by the Young's equation[4]:

$$
\sigma_{S}=\sigma_{S L}+\sigma_{L} \cos \theta_{Y}
$$

wherein $\sigma_{S}$ is the overall surface energy of a solid surface, $\sigma_{L}$ - the overall surface tension of a wetting liquid, $\sigma_{\mathrm{SL}}$ - the interfacial tension between a solid and a liquid, and $\theta_{\mathrm{Y}}$ - the liquid contact angle. When water is brought into contact with a solid that has a lower surface energy, the contact area of water with the solid is minimised. In particular, spherical drops with high contact and low roll-off angles can be observed. Such effects are witnessed in nature, e.g. on Lotus leaves or on legs of Microvelia, and can be partially attributed to specific surface topographies that are at micro and nano scales[5]. Numerous attempts to reproduce such bioinspired hydrophobic surface structures have been reported[6]. One growing means to manufacture surfaces with a tailored wettability is the use of ultra-short pulsed lasers[7,8]. This route to fabricate micropatterns, nanoripples or dual-scale structures has been investigated by many researchers. However, the evolution of their respective surface chemistry in ambient air or storage conditions is less studied while it is of prime importance in retaining the attractive surface functionality for as long as possible[9-11]. At the same time another indirect route for enhancing the hydrophobic properties of chemically stable polymers is gaining importance, especially through the use of well-established replication processes to transfer laser-fabricated surface textures/structures on tooling inserts onto thermoplastic parts[12-14]. 
Wenzel and Cassie-Baxter models describe equilibrium states and define the functional dependence between the equilibrium contact angle of a plane surface, $\theta_{Y}$, and the contact angle of a structured one, $\theta_{W}$. Especially, Wenzel introduces in the model the roughness ratio $\left(r_{W} \geq 1\right)$ that is the fraction of developed/processed areas of a solid over its nominal one[15]:

$$
\cos \theta_{W}=\mathrm{r}_{W} \cos \theta_{Y}
$$

As it is well-known, Equation 2 confirms that for hydrophobic materials the surface roughness increases the hydrophobicity. In the superhydrophobic regime, when the water contact angle is higher than $150^{\circ}$, the Cassie-Baxter (CB) model[16] describes the entrapment of air pockets onto the surface structures/textures:

$$
\cos \theta_{C B}=-1+\varphi_{C B}\left(\cos \theta_{Y}+1\right)
$$

where the filling ratio $\left(\varphi_{\mathrm{CB}} \leq 1\right)$ distinguishes the fraction of solid that is in contact with the liquid. The Cassie-Baxter state is usually metastable and a potential imbibition can lead to Wenzel state, i.e. wetting of the surface structures[17].

To assess the functional response of easy-to-clean surfaces, their cleanability has to be investigated. During the products' lifetime, any damage to surface topographies will inevitably impact their wetting behaviour, i.e. contact angle values, and thus will affect the desirable functional surface response. Therefore, any mechanical abrasion and surface wear play a very important role in assessing products' durability as a whole. In addition, no standardized cleanability test exists to validate the product durability and usually water contact angle measurements are taken after harsh mechanical abrasion to judge about the surfaces' functional degradation[18-21].

This paper reports an investigation on the mechanical durability of textured thermoplastic surfaces. Laser-induced topographies with different aspect ratios from micro to nanoscale were 
fabricated on mould inserts employing an ultrashort pulsed laser. Then, polypropylene replicas were produced through micro-injection moulding. In this way, hierarchical surface topographies exhibiting the Cassie-Baxter state were "imprinted" on thermoplastic replicas. Their durability was assessed by performing cleaning cycles in reciprocating mode and thus to quantify the impact of mechanical abrasion on surface topology and its wetting property. Finally, the interdependencies between standardised 3D areal parameters and surface functionality, i.e. wettability, were analysed to identify correlations between them.

\section{Materials and methods}

\subsection{Laser texturing of inserts}

A mould steel bar with grade 1.4021 (Uddeholm Stavax ESR) was machined to produce inserts with dimensions $\varnothing 10 \mathrm{~mm}$ x $7 \mathrm{~mm}$. The insert surfaces were polished to $40 \mathrm{~nm}$ (Sa). The process chain is illustrated in Fig. 1a. Then, the inserts were textured by employing a laser source with pulse length of $310 \mathrm{fs}$ and wavelength of $1032 \mathrm{~nm}$ (Amplitude Systemes Satsuma). A 3D scan head (RhoThor RTA) was used to steer a spot diameter of $30 \mu \mathrm{m}$ in the focal plane (see Fig. 1b). In this way, different laser-based texturing techniques were employed to fabricate a broad range of micro/nano scale topographies on the steel inserts. In the case of microsphere-assisted "Photonic Jet" (PJ) texturing, a preliminary step was required, involving the deposition of a hexagonal closely-packed monolayer of $1 \mu \mathrm{m} \mathrm{SiO}_{2}$ microspheres onto a hydrophilic sacrificial substrate using the Langmuir-Blodgett technique and its transfer onto the insert using a highly transparent adhesive (Nitto CS9862UA). Irradiating of such surface preparation resulted in microsphere- 
assisted direct laser ablation and the fabrication of array of submicron holes. Furthermore, LaserInduced Periodic Surface Structures (LIPSS) processing was used to produce a regular 1D submicron grating with a periodicity close to the laser wavelength, using a linear laser polarisation and high pulse overlap strategy to form homogeneous linear-like ripples on the insert surface. Finally, micro scale ablation was used to manufacture lotus-inspired morphologies with different aspect ratios and grid structures by varying the spatial distance between intersecting grooves. The process settings used to laser texture eight inserts (detailed in Table 1) were selected based on reported results $[7,10,22-25]$ and some preliminary trials. After the laser texturing operation, the inserts were first sonicated in ethanol bath for $15 \mathrm{~min}$ and then rinsed with water and air dried.

\subsection{Micro-injection moulding}

Polypropylene (PP) is commonly used for injection moulding polymer parts for many application areas, e.g. in producing home appliances, automobile air ducting parts, wet-cell battery cases, pipes and pipefittings, etc. Therefore, a polypropylene-homopolymer (PP) compound (Ineos PP 100-GA12) in the form of a translucent non-polar thermoplastic was selected to investigate the durability of different surface topographies.

The replication process was performed employing a state-of-the-art micro-injection moulding (micromoulding) machine (Wittmann Battenfeld MicroPower 15). A schematic of the micromoulding set-up is provided in Fig. 1c. Based on the material manufacturer's datasheet and some initial trials, the heating profile was set to increase progressively along the four defined zones from the hopper to the nozzle with values of $200,200,215$ and $230{ }^{\circ} \mathrm{C}$, respectively. The temperatures of the moving and fixed halves of the mould were controlled using pairs of cartridge 
heaters and J-type thermocouples. The textured inserts were integrated into a modular tool and polypropylene parts with outer circular cavity of $\varnothing 17 \mathrm{~mm}$ and $0.5 \mathrm{~mm}$ thickness were produced. The textured area was located in the middle of the outer cavity of the polymer parts with a diameter of $10 \mathrm{~mm}$ as illustrated in Fig. 1. Micromoulding was carried out using an injection pressure of $400 \mathrm{bar}$ and an injection speed of $200 \mathrm{~mm} / \mathrm{s}$. After the filling stage a holding pressure of $450 \mathrm{bar}$ was applied for $5 \mathrm{~s}$. The micromoulding cycle time was $25 \mathrm{~s}$ and its four stages are shown in Fig. 1d. Micromoulding studies reported in the literature[26-28] and the initial trials showed that mould temperature and holding pressure were the most important factors affecting the replication quality of micro/nano features. Therefore, two different levels for mould temperature $\left(60\right.$ and $\left.80{ }^{\circ} \mathrm{C}\right)$ and holding pressure (450 and 700 bar) were used. Further moulding trials were performed and micromoulded parts were visually inspected to avoid burrs and demoulding defects. The topographies achieved on textured surfaces were investigated to maximise their aspect ratio and replication quality. The replication process was stable after 20 micromoulding cycles and then batches of 50 samples were produced using the eight textured inserts and one polished reference insert. The parts were produced without using any demoulding agent and thus to avoid potential contaminations of replicas and to ensure a good replication of textured surfaces.

\subsection{Abrasion test}

The mechanical durability of the textured polymer samples was assessed by adapting the ASTM D3450 standard that was originally developed for abrasion tests of coatings[29]. In particular, the micromoulded discs were positioned in a washability tester (Elcometer 1720) and a multipurpose cloth (Ubesol, composition: 60\% Viscose, 25\% Polyester, 15\% Polypropylene) was used as 
counterpart in the cleaning cycles. The cloth fibres had a diameter of approximately $13 \mu \mathrm{m}$. The cycles were performed in reciprocating mode with a total dry load of $0.05 \mathrm{kgf} / \mathrm{cm}^{2}$. The texture orientation in regard to the reciprocating movement was randomised. The $180-\mathrm{mm}$ full stroke length was performed at 37 cycles/min. The cloth was renewed every 125 cycles. For the test in the wet conditions, $15 \mathrm{ml}$ of detergent (Fairy original) dissolved at 3:100 into distilled water was poured into the tribological contact every 75 cycles. To remove any debris and detergent before analysing the surface topology evolution and functional response, the samples were rinsed 3 times with water and air dried.

\subsection{Surface topography}

The morphologies of textured thermoplastic samples were analysed using a focus variation microscope (Alicona G5) with 50x and 100x magnification objectives, in particular with lateral and vertical resolutions of up to $440 \mathrm{~nm}$ and $10 \mathrm{~nm}$, respectively. The 3D areal parameters were acquired by the Alicona IF-MeasureSuite 4.1 software according to the ISO 25178-2:2012 standard [30]. The statistical analysis of areal parameters for textured steel $(n=3)$ and polymer replicas $(n=9)$ was performed in Minitab 17.1.0. 3D topographical inspections were carried out employing a scanning electron microscope (Hitachi TEM3030Plus) with a back-scattered secondary electron detector and low vacuum. The 2D Fast Fourier Transforms (FFT) of the SEM images were performed with Gwyddion 2.51 to characterize the periodic patterns. 


\subsection{Wettability and surface energy}

Each of the surfaces' wetting properties were characterised under ambient conditions using an optical tensiometer (Attension Biolin Scientific Theta T2000-Basic+). Static contact angles $(\theta)$ were measured using the sessile drop technique, after stabilisation of a $6 \mu$ sessile drop on the surface and by applying the Young-Laplace fitting method. Dynamic contact angles were studied by dispensing $30 \mu \mathrm{l}$ of liquid at $0.5 \mu \mathrm{l} / \mathrm{s}$ with the needle-in-drop method and thus to measure the evolution of quasi-static contact angles. Cycles of volume increase and decrease were performed until the values had stabilised for determining advancing $\left(\theta_{\mathrm{adv}}\right)$ and receding $\left(\theta_{\mathrm{rec}}\right)$ angles, respectively. The contact angle hysteresis $\left(\theta_{\mathrm{H}}\right)$ was defined as the maximum value obtained with the two methods, i.e. either the difference between the advancing and receding contact angles or using the inclined plate method up to $45^{\circ}$.

The surface energies were quantified using a simplified Fowkes' two-component model developed by Owens and Wendt[31]. The overall surface energy $(\sigma)$ of a liquid or a solid is considered as the sum of two intramolecular components; a dispersive $\left(\sigma^{\mathrm{D}}\right)$ and a polar $\left(\sigma^{\mathrm{P}}\right)$ contributions that are assumed to equal:

$$
\sigma=\sigma^{D}+\sigma^{P}
$$

Static contact angles were measured with two liquids, purified milli-Q water and diiodomethane, which surface tension components are detailed in Table 2. Diiodomethane $\left(\mathrm{CH}_{2} \mathrm{I}_{2}\right)$ is used as nonpolar probe liquid $\left(\sigma^{\mathrm{P}}=0\right)$ because of its relatively high overall surface tension, while having a molecular symmetry. The surface tension components of textured surfaces were approximated using a geometric mean approach[31]:

$$
\sigma_{S L}=\sigma_{S}+\sigma_{L}-2 \sqrt{\sigma_{L}^{D} \sigma_{S}^{D}}-2 \sqrt{\sigma_{L}^{P} \sigma_{S}^{P}}
$$


Assuming complete wetting $\left(\theta=0^{\circ}\right)$, the wetting envelopes of the solid surfaces were calculated with the following equation:

$$
\mathrm{R}=\left(\frac{\sqrt{\sigma_{S}^{D} \cos \varphi}+\sqrt{\sigma_{S}^{P} \sin \varphi}}{\cos \varphi+\sin \varphi}\right)^{2}
$$

where $0 \leq \mathrm{R}$ and $0^{\circ} \leq \varphi \leq 90^{\circ}$ are the polar coordinates.

The work of adhesion $\left(\mathrm{W}_{\mathrm{SL}}\right)$ refers to the force required to separate the solid-liquid interface and can be described with the free energy of adhesion $\left(\Delta \mathrm{G}_{\mathrm{SL}}\right)$ that is measured using the Young-Dupré equation[32]:

$$
W_{S L}=-\Delta G_{S L}=\sigma_{L}(1+\cos \theta)
$$

\section{Results and discussion}

\subsection{Replication of laser-textured surfaces}

Fig. 2 shows the SEM micrographs of surface textures on the eight inserts processed with the laser texturing methods/strategies described in Table 1.

An array of submicron holes was fabricated on Insert 1 using a microsphere-assisted near field focusing technique. As described in Section 2.1, a prerequisite to this laser texturing method is the deposition of a closely-packed microspheres' monolayer. The laser beam is focused beneath each microsphere by creating PJs. Upon the laser irradiation, the energy is sufficient to ablate material. Holes of $\varnothing 0.57 \mu \mathrm{m}$ with standard deviation of $0.15 \mu \mathrm{m}$ were generated. As a hexagonal closelypacked monolayer of microspheres was used, the periodicity of the resulting array of holes was equal to their diameter, i.e. $1 \mu \mathrm{m}$. 
A submicron grating was generated on Insert 2. The self-organised LIPSS structures were created with fluence per pulse of $0.09 \mathrm{~J} / \mathrm{cm}^{2}$, close to the LIPSS generation threshold. The linearlike LIPSS are oriented perpendicular to the laser polarisation. The periodicity of the ripples is approximately $0.93 \mu \mathrm{m}$. The width of the ripples' ridges is approximately half of their periodicity.

By using a circular polarisation, the ripples' orientation was changed to $45^{\circ}$ relatively to the scanning direction. By increasing the pulse fluence to $1.1 \mathrm{~J} / \mathrm{cm}^{2}$, the submicron ripples were maintained while another type of LIPSS were generated at the microscale that was perpendicular to the previous ones. At this pulse fluence, the high pulse overlap led to ablation of material and grooves were formed with a width equal to the beam spot diameter of $30 \mu \mathrm{m}$. Even though material was ablated, multi-scale LIPSS topographies covered the grooves as shown in Fig. 2 (Inserts 3 and 4). The depth of the grooves could be increased with the number of scans.

By using these laser settings and by intersecting the laser scans, various surface topographies were fabricated on Inserts 3 to 8 . In particular, multi-scale topographies were obtained on Insert 3 by scanning 10 times the surface. At the same time intersecting laser scans led to the formation of microscale topographies consisting of peaks and valleys with aspect ratios $0.1,0.3$ and 0.9 for Inserts 3, 4 and 5, respectively. The processed areas were fully covered with LIPSS that had two distinguishable periodicities, one below the laser wavelength and the other above it. Sporadic holes were generated as a result of the increased number of scans. Especially, uncontrolled holes' formation was observed when the accumulated fluence reached the ablation threshold of the material. This physical effect was used to fabricate more complex surface geometries on Inserts 6 to 8 , i.e. surface topographies with lower texturing density. The spatial distance between the intersecting scans was increased to exceed the laser spot diameter and thus to create more defined groove structures with larger untextured areas. 
The textured surfaces of the steel inserts were replicated onto the polypropylene discs via micromoulding as shown in Fig. 3. Even though no release agent was used in the process, no trace of polymer was observed on the cavity insert after demoulding. Insert 5 had the highest aspect ratio and was inspected closely but no noticeable polymeric debris were observed after 100 moulding cycles. Diffractive light scattering effects on the discs' textured surfaces obtained with Inserts 1 and 2 were observed as well, indicating a good qualitative replication of submicron patterns.

The previously discussed surface periodicities are depicted in Fig. 4a. It appears that an increase of scanning repetitions led to a periodicity increase or decrease of the smaller and larger LIPSS, respectively. The FFT of the microscale topographies gave periodicities slightly larger than the laser pitch distance due to the cross-like texturing strategy.

Two representative areal parameters were used to assess the quality of replicated surface topographies. In particular, the arithmetical mean height $(\mathrm{Sa})$ and the maximal height $(\mathrm{Sz})$ were found to be consistent on as-fabricated and replicated topographies as shown in Fig. 4b-c. In case of multi scale topographies, Sz values remained lower on replicas. Polypropylene exhibits a shrinkage up to $2 \%[33]$ that could affect the aspect ratio of replicated topographies but at the same time is beneficial during demoulding. Nevertheless, Sa values of replicated microstructures were within 90 to $105 \%$ of those obtained on Inserts 3 to 8 . The focus variation microscope did not acquire sufficient data points from the surfaces of the PP0, PP1 and PP2 samples, due to their nano scale texturing and the transparency of the material. In the case of the untextured replica, no values were obtained. For PP1 and PP2, Sa and Sz values were larger than those on their respective inserts. This is potentially due to deformation during ejection caused by mould adhesion during the replication process. Sa remained below $0.15 \mu \mathrm{m}$ while $\mathrm{Sz}$ reached $1.8 \mu \mathrm{m}$ for submicron textures 
on the PP1 and PP2 samples. The peak to peak values of the PP5 samples were slightly higher than those on Insert 5, whereas Sz of the PP4 samples reached only 75\% of those obtained on Insert 4. Such variations may be explained with the low number of data points obtained at the bottom of valley's interstices and the sporadic holes.

\subsection{Wettability of laser-textured replicated surfaces}

The wettability of different topographies micromoulded on PP1 to PP8 samples was assessed. The average results from 3 measurements are provided in Table 3 . The physicochemistry of the polymer is considered not altered by the micromoulding process. The polymer parts are therefore assumed to remain inert and possess a stable surface chemistry over time. Indeed, no significant variations of water contact angles were observed after storing them for several weeks or after cleaning the surfaces. The homogeneous flat surfaces of the PP0 samples were taken as a reference, i.e. with a water contact angle larger than $90^{\circ}$ and a hysteresis larger than $10^{\circ}$. PP0 is slightly hydrophobic and water is "pinned" onto the surface. As predicted by the Wenzel equation, any increase in surface roughness led to a higher water contact angle (see Fig. 5a). Moreover, surface roughness had the tendency to increase the contact angle hysteresis, preventing the water drop from rolling off the surface. At the same time, submicron topographies, i.e. on the PP1 and PP2 samples, or low aspect ratio micro textures, i.e. on the PP3 and PP4 samples, did not significantly change the hysteresis but a further increase of Sa and Sz led to more than doubling of the $\theta_{\mathrm{H}}$ value, i.e. on the PP6 and PP7 samples.

Using Equation 4 and 5, the surface energies and polar components of micromoulded samples were calculated (see Table 3 and Fig. 5b). The surface energy remained similar between the PP0 
and PP1 samples while it increased for LIPSS and Lotus textures (PP2 to PP5) and reduced for grid textures with the larger spacing (PP6 to PP8). The homopolymer chains $\left(\mathrm{C}_{3} \mathrm{H}_{6}\right)_{n}$ present in polypropylene are non-polar molecules. Accordingly, the polar component of surface energy remained close to 0 for the non-textured and most of low aspect ratio textured replicas. The polar component was the highest for the PP5 samples and reached similar levels as corona-dischargetreated polypropylene[34], though remained stable over time. The replication of surface topography by micromoulding resulted in an increased surface roughness, too, and also appeared to create a polar state that might inhibit the necessary plasma activation if bonding is required. Therefore, the effects of the polar state on potential follow up plasma activation operations should be investigated further.

Equation 6 was used to plot the wetting envelopes of micromoulded surfaces as shown in Fig. 5c. The plotted lines indicate the scale of adhesive forces at the liquid/solid interface that are necessary to overcome the cohesive forces within the liquid and would result in complete wetting of the surface $\left(\theta=0^{\circ}\right)$. The resulting graph shows the expected wettability of any liquids on the investigated textured polypropylene surfaces. No polar components were calculated with Equations 4 and 5 for the reference as shown in Fig. $5 \mathrm{~b}$, but a polar component close to $7 \mathrm{~mJ} / \mathrm{m}^{2}$ was observed for the PP5 samples. Nanotextures on the PP1 samples did not affect the surface energy or the wetting envelope significantly. The LIPSS morphologies on the PP2 samples enlarged the area enclosed by the wetting envelope. In regard to the surface energy components, the dual scale topographies on the PP3 samples had the same effect as those on the PP2 ones. The PP4 envelope is enlarged slightly towards the dispersive component while the PP5 one has the largest overall enclosed area due to the bigger polar component. On the contrary, the areas enclosed by the PP6, 7 and 8 envelopes are significantly smaller despite their higher polar components 
compared with the reference. At the same time, their surfaces have the lower surface energy per unit area and the reasons for this should be investigated further. The graphs show that a good wetting can be expected if low polar and low surface tension liquids, such as oils and adhesives, are used.

The free surface energy was calculated using Equation 7. From the formula, it can be expected that a lower contact angle entails a higher work of adhesion $\mathrm{W}_{\mathrm{SL}}$ and thus more energy would be required to separate the solid-liquid interface. Indeed, the absolute value of $\Delta \mathrm{G}_{\mathrm{SL}}$ was the highest for the PP0 samples and then dropped strongly with the increase of roughness and aspect ratios. In the superhydrophobic regime, the water contact angle needs to be larger than $150^{\circ}$ and the rolling angle should be lower than $10^{\circ}$. In such case, the surface exhibits low contact angle hysteresis and little energy would be required to separate a liquid drop from the textured surface. However, the topologies with the high aspect ratio had a detrimental effect on $\theta_{\mathrm{H}}$ and the values for all textured surfaces were higher than the reference of $13.3^{\circ}$, hence preventing water drops to roll out of the micromoulded surfaces. Only the textured surfaces on the PP5 samples were superhydrophobic with $\theta=159.9^{\circ}$ and a rolling angle estimated to be below $5^{\circ}$. The rolling was assessed by dropping a sufficient volume of water on a slightly tilted surface so that the gravity releases the water drop from the needle. PP5's rolling angle could not be measured accurately, as the water drop could only be deposited by applying a gentle pressure that resulted in wetting the surface and "pinning" the water drop onto the high aspect ratio surface topography as shown in Fig. 6a.

Starting with a contact angle of $105.7^{\circ}$ on the reference PP0 samples, the theoretical value of 3.20 for $r_{W}$ is required to achieve a superhydrophobic regime, i.e. $\theta=150^{\circ}$. However, the maximum $r_{W}$ value measured in this research was 2.80 , confirming that the Wenzel regime didn't apply on all topographies. Also, based on the experiments carried out in this research it could be stated that 
it is more probable to reach a Cassie-Baxter state when $r_{W}$ is higher, as expected. The CassieBaxter $\left(\varphi_{\mathrm{CB}}\right)$ and Wenzel ( $\left.\mathrm{r}_{\mathrm{W}}\right)$ factors were calculated by using the apparent contact angle and the one after inducing micro vibration on the samples. In this way, it was possible to avoid metastable regimes and reach the most stable Wenzel state. The values are provided in Table 3 . The CassieBaxter state is very pronounced on the textured surfaces of the PP5 samples $\left(\varphi_{\mathrm{CB}}<<1\right)$, however it is metastable as depicted in Fig. 6b. Micro vibrations could reduce the contact angles from superhydrophobic to lower hydrophobic states. All other investigated surface topographies were either in full Wenzel or mixed Cassie-Baxter/Wenzel states (see Fig. 6c).

\subsection{Effects of cleaning cycles on surface functionality}

The robustness of textured polymeric surfaces was assessed by performing reciprocating abrasion cycles in both wet and dry environments. These specifically designed cleaning cycles were aimed to mimic real-life cleaning routines on surfaces (see section 2.3). The number of cycles was varied to study the progressive damage imposed to the micromoulded surfaces. The asperities of the investigated topographies were the first entities to be in tribological contact with the cleaning cloths and this can explain why they were progressively abraded and worn, as shown in Fig. 7 for the PP5 to PP7 samples. Wet cycles did not abrade the surfaces significantly when compared to the dry cycles. Especially, only the asperities of investigated PP microscale topographies were abraded after 1000 cycles in wet conditions. In dry conditions, the lotus-inspired topographies exhibited the highest sensitivity to wear and the surfaces were abraded, forming new structures with square-periodic micropatterns without dual-scale topographies. 
The evolution of surface topography was measured after 1000 wet and dry cleaning cycles of the textured polymer. Due to the broad variations of surface topographies and roughness scales, the absolute values are displayed in Table 2 and the relative evolution in percentage of $\mathrm{Sa}, \mathrm{Sz}$ and F, normalized with the measurements before cleaning, are presented in Fig. 8. There were relative increases of Sa and Sz values for the PP0 to PP2 samples, however in the PP2 case an increase was obtained only after the dry cleaning cycles. All micro-scale topographies, i.e. on PP3 to PP8 samples, exhibited a decrease of Sa and $\mathrm{Sz}$ by $25 \%$ and $40 \%$ in dry conditions, respectively, as shown in Fig. 8a-b. The spread of the Sa values based on 9 measurements was within $+5 \%$ and $10 \%$, after the wet cycles while much bigger deviations were observed for Sz after the dry cycles. Moreover, the ratio between measured and projected topographies, another standardised parameter, that again can be obtained directly with the measurement systems, is displayed in Fig. 8c. As the F ratio has the same definition as the Wenzel roughness (see Section 1), it is used to give further indication about the wetting properties of the polymer replicas. The overall evolution of $\mathrm{F}$ after the abrasive cleaning cycles was similar to that obtained for $\mathrm{Sa}$ and $\mathrm{Sz}$ on the samples with microscale topographies, i.e. PP3 to PP8. The maximum F value of 1.73 was measured on the initial PP5 surface but was not retained after the abrasive cycles. In particular, F decreased significantly after 1000 dry cycles to values below 1.10 for the PP6 to PP8 samples. At the same time, it should be noted that the resolution of the measurement devices did not allow a higher $\mathrm{F}$ to be obtained on submicron topographies, i.e. on the PP1 and PP2 samples. The low aspect ratio topographies on the PP3 and PP4 samples had also F values below 1.10 that decreased slightly after the abrasion cycles.

As the topographical changes affected the surface functionality, the evolution of wettability was assessed after the abrasive cycles on micromoulded surfaces. The wetting properties were affected 
even after a low number of cycles, a minimum of 250 cycles being considered in this study. Overall, the wettability was retained within $+/-10 \%$ of the reference values after 500 and 1000 cycles on all samples except PP1 and PP5. The water contact angle measurements after 1000 wet and dry cycles are provided in Fig. 9a. The progressive decrease of $\theta$ was similar for the PP6 to PP8 samples, signifying that a large spatial distance between intersecting grooves is nonsignificant for the mechanical robustness. For the reference PP0 sample and those with submicron roughness, such as the PP1 sample, a significant drop of $\theta$ was observed, especially below the reference value and in some cases, even below $90^{\circ}$. This could be explained with the increase of surface roughness, agglomeration of debris or re-entrant topographies with capillarity properties. The repeated reciprocating cycles in dry conditions could create wear tracks leading to a higher $\theta$, as it was the case with the PP0 to PP4 samples and this is highlighted in Fig. 9b. Regarding the PP5 samples, the Cassie-Baxter state seems to be lost after first contact with the surface. However, if it is compared with the Wenzel regime $\left(\theta_{\mathrm{PP} 5^{*}}=139.2^{\circ}\right)$, the wetting properties could be retained within $+/-2 \%$ and $+/-10 \%$ after 1000 wet cycles and dry cycles, respectively. Dynamic contact angle measurements were performed on the cleaned PP5 surfaces, too, as shown in Fig. 9c. The advancing and receding angles remained similar after 1000 wet cycles on the PP5 samples, however the same advancing angle was reached when the drop volume increased from 2 to $10 \mu 1$. The maximum advancing contact angle for the PP5 samples after 1000 wet cycles was found close to the values obtained on as-micromoulded surfaces $\left(>150^{\circ}\right)$. The asperities of the lotus-liked valleys were certainly abraded and lost their as-micromoulded roughness. Nevertheless, the PP5 surfaces managed to retain to some extent part of their wetting properties. Topographies similar to those on the PP5 samples could be considered as a starting point for a further research into robust functional surfaces, potentially by increasing the aspect ratio of considered topographies in this 
research. Especially, such follow up research should provide an answer whether it would be possible to demould parts from inserts incorporating higher aspect ratio topographies.

\subsection{D areal parameters vs. wettability}

The 3D areal parameters measured on as-micromoulded surfaces are provided in Table 4. These parameters were analysed with the aim to identify interdependences between topographies and their resulting functional responses, i.e. wettability. In this section, the complete dataset acquired in this research $(\mathrm{n}=62)$ is used. It should be noted that standardised 3D areal parameters were used to characterize the surface topographies and such data could be acquired with any state of the art surface characterisation systems, e.g. as Alicona G5 in this research. For wettability, a normalised value, i.e. $\cos (\theta) / \cos \left(\theta_{\mathrm{Y}}\right)$, equivalent to the Wenzel roughness coefficient $\left(\mathrm{r}_{\mathrm{Weq}}\right)$ is used. First, the evolution of $\mathrm{r}_{\mathrm{Weq}}$ was compared to the F values in Fig. 10a. While a general trend could be identified, the comparison did not suggest any clear linear regression and a significant deviation from the theoretical contact angles, calculated using Equation 2, was noticed.

The F ratio seems to be strongly linked to Sa and Sz (see Fig. 10b). However, to have a better understanding of interdependences between wettability and surface topography, a correlation analysis was carried out between the obtained contact angles (normalised as $\mathrm{r}_{\mathrm{Weq}}$ ) and 3D areal parameters Sa, Sq, Sz, Sk, Sdr and F (see Fig. 10c). The highest Pearson correlation coefficient was obtained for the peak-to-peak height $\mathrm{Sz}(\mathrm{r}=0.85)$ followed closely by Sa and then Sq. The skewness Ssk could be considered non-correlated to wettability or the other 3D areal parameters ( $\mathrm{r}$ between 0.02 and 0.2 ). The $\mathrm{F}$ factor evolved similarly to $\mathrm{Sa}$ and $\mathrm{Sz}$, but its highest linear correlation was with the developed interfacial ratio, $\operatorname{Sdr}(\mathrm{r}=0.97)$, in particular F and $\mathrm{Sdr}$ increased 
for topographies with high density or aspect ratio. In addition, the effects of two positive factors, $\mathrm{F}$ and $\mathrm{r}_{\mathrm{Weq}}$, in regard to the true to nominal surface ratios were compared. There were differences in $\mathrm{F}$ and $\mathrm{r}_{\mathrm{Weq}}$ effects but both showed a similar trend, i.e. wettability increased with $\mathrm{F}$. Sa, Sq and Sz were strongly linearly correlated between each other $(r>0.97)$. The strongest correlation of Sk was with $\mathrm{Sa}(\mathrm{r}=0.97)$. A predicative analysis was performed to study the relationship between wettability and investigated topographies (see Fig. 10d). The 3D areal parameters with high correlation to surface wettability were identified as $\mathrm{Sa}, \mathrm{Sq}, \mathrm{Sz}, \mathrm{Sk}, \mathrm{Sdr}$ and F. At the same time, Sku and Ssk were discarded as their relation to the surface functional response was below $20 \%$. Therefore, taking into account the correlations between considered areal parameters it could be sufficient to use Sa or Sz together with F to assess the wetting properties of surface topographies investigated in this research. Further research could be carried out in order to quantify the contribution of such 3D areal factors on the Cassie-Baxter state, especially regarding superhydrophobicity.

\section{Conclusion}

The durability of textured polymeric surfaces was investigated. A process chain combining ultrashort pulsed laser texturing of tool steel inserts with micromoulding of polypropylene parts was deployed. In that way, multi-scale laser-based topographies were fabricated on polypropylene surfaces. The textured samples exhibited different wetting states from hydrophobic to superhydrophobic that were quantified in terms of surface energy and surface free energy. Also, the wetting states were quantified by estimating their Wenzel and Cassie-Baxter factors. 
Cleanability tests were performed with multipurpose cloths in reciprocating cycles. The mechanical abrasion of the textured surfaces led to a decrease of water contact angle. The topographies with a sole submicron roughness were not found sufficiently robust to withstand the cleaning cycles. On the contrary, the dual scale textures exhibited a minimal wear and thus to some extend were able to retain the surface topographies together their respective wetting properties. The wet cleaning cycles were found to be much less harsh to the surface textures and surface functionalities. Thus, it would be possible to define wet cleaning procedures that textured polymer surfaces could withstand with minimal deterioration of their wetting properties. In this way, the subtle metastable Cassie-Baxter state could be maintained and hence the desired superhydrophobic properties.

The empirical data gathered in the experiments suggest that the 3D areal parameters with a high correlation to surface wettability are Sa, Sq, Sz, Sk, Sdr and F. At the same time, it was found that Sku and Ssk had very low correlation, i.e. below $20 \%$, to the surface wetting properties. Therefore, taking into account the identified correlations between 3D areal parameters, a small number of 3D areal parameters, e.g. Sa or Sz together with F in this research, could be considered to judge about the wetting properties of surface topographies on polypropylene parts. Such standardised areal parameters can be obtained readily using any state-of-the-art surface characterisation system and could be used to define inspection routines and also to estimate indirectly the current state of surfaces' functional response. 


\section{TABLES}

Table 1: The process settings used to laser texture steel inserts.

\begin{tabular}{|c|c|c|c|c|c|c|c|c|}
\hline $\mathrm{Nr}$. & Description & $\begin{array}{l}\text { Power } \\
\text { (W) }\end{array}$ & $\begin{array}{l}\text { Rep. Rate } \\
(\mathrm{kHz})\end{array}$ & $\begin{array}{l}\text { Speed } \\
(\mathrm{mm} / \mathrm{s})\end{array}$ & $\begin{array}{l}\text { Pitch } \\
(\mu \mathrm{m})\end{array}$ & $\begin{array}{l}\text { Focal } \\
\text { offset } \\
(\mathrm{mm})\end{array}$ & $\begin{array}{l}\text { Layer } \\
(-)\end{array}$ & Strategy \\
\hline 0 & Untextured & - & - & - & - & - & - & - \\
\hline 1 & Array of holes & 0.245 & 100 & 1000 & 10 & -1 & 1 & Horizontal \\
\hline 2 & LIPSS & 0.330 & 500 & 2000 & 2 & 0 & 1 & Horizontal \\
\hline 3 & Lotus 1 & 1.975 & 250 & 500 & 25 & 0 & 10 & Grid \\
\hline 4 & Lotus2 & 1.975 & 250 & 500 & 25 & 0 & 20 & Grid \\
\hline 5 & Lotus3 & 1.975 & 250 & 500 & 25 & 0 & 50 & Grid \\
\hline 6 & Grid1 & 3.945 & 500 & 500 & 40 & 0 & 20 & Grid \\
\hline 7 & Grid2 & 3.945 & 500 & 500 & 60 & 0 & 20 & Grid \\
\hline 8 & Grid3 & 3.945 & 500 & 500 & 80 & 0 & 20 & Grid \\
\hline
\end{tabular}


Table 2: Surface energy components of water and diiodomethane.

\begin{tabular}{|c|c|c|c|}
\hline & $\begin{array}{l}\text { Surface energy } \\
\sigma_{\mathrm{L}}\left(\mathrm{mJ} / \mathrm{m}^{2}\right)\end{array}$ & $\begin{array}{l}\text { Dispersive component } \\
\sigma^{D_{L}}\left(\mathrm{~mJ} / \mathrm{m}^{2}\right)\end{array}$ & $\begin{array}{l}\text { Polar component } \\
\sigma_{\mathrm{L}}^{\mathrm{P}}\left(\mathrm{mJ} / \mathrm{m}^{2}\right)\end{array}$ \\
\hline Water & 72.8 & 21.8 & 51.0 \\
\hline Diiodomethane & 50.8 & 50.8 & 0.0 \\
\hline
\end{tabular}


Table 3: Wettability analysis of polypropylene replicas, the average results from 3 measurements.

\begin{tabular}{|c|c|c|c|c|c|c|c|}
\hline $\mathrm{Nr}$. & $\begin{array}{l}\theta \\
\left(^{\circ}\right)\end{array}$ & $\begin{array}{l}\theta_{\mathrm{H}} \\
\left(^{\circ}\right)\end{array}$ & $\begin{array}{l}\sigma_{\mathrm{S}} \\
\left(\mathrm{mJ} / \mathrm{m}^{2}\right)\end{array}$ & $\begin{array}{l}\sigma_{\mathrm{S}}^{\mathrm{P}} \\
\left(\mathrm{mJ} / \mathrm{m}^{2}\right)\end{array}$ & $\begin{array}{l}\Delta \mathrm{GSL}_{\mathrm{SL}} \\
\left(\mathrm{mJ} / \mathrm{m}^{2}\right)\end{array}$ & $\begin{array}{l}\mathrm{r}_{\mathrm{W}} \\
(-)\end{array}$ & $\begin{array}{l}\varphi_{\mathrm{CB}} \\
(-)\end{array}$ \\
\hline PP0 & 105.7 & 13.3 & 27.4 & 0.1 & -53.1 & $1.00^{*}$ & 1.00 \\
\hline PP1 & 109.1 & 13.8 & 27.8 & 0.0 & -48.9 & $1.21^{*}$ & 0.92 \\
\hline PP2 & 115.0 & 13.7 & 31.4 & 0.5 & -42.1 & $1.56^{*}$ & 0.79 \\
\hline PP3 & 115.9 & 14.3 & 31.6 & 0.6 & -41.0 & $1.62^{*}$ & 0.77 \\
\hline PP4 & 124.3 & 15.9 & 34.5 & 2.2 & -31.8 & $2.08^{*}$ & 0.60 \\
\hline PP5 & 159.9 & $27.0^{*}$ & 36.2 & 9.4 & -4.4 & $2.80^{*}$ & 0.08 \\
\hline PP6 & 142.5 & 33.9 & 17.6 & 2.3 & -15.0 & $2.69^{*}$ & 0.28 \\
\hline PP7 & 142.3 & 34.2 & 15.6 & 1.8 & -15.2 & $2.59^{*}$ & 0.29 \\
\hline PP8 & 133.0 & 23.3 & 16.6 & 0.9 & -23.2 & $1.97^{*}$ & 0.44 \\
\hline
\end{tabular}

Notes: $\theta$ - water contact angle; $\theta_{\mathrm{H}}$ - contact angle hysteresis; $\sigma_{\mathrm{S}}$ - surface energy; $\sigma_{\mathrm{S}}^{\mathrm{P}}$ - the polar component; $\Delta \mathrm{G}_{\mathrm{SL}}$ - surface free energy; $\mathrm{r}_{\mathrm{W}}$ - calculated Wenzel roughness; $\varphi_{\mathrm{CB}}$ - calculated CassieBaxter factor ("Wenzel state). 
Table 4: The 3D areal surface parameters and the respective Wenzel factor of the textured polypropylene samples.

\begin{tabular}{|c|c|c|c|c|c|c|c|c|c|}
\hline Nr. & $\begin{array}{l}\text { Sa } \\
(\mu \mathrm{m})\end{array}$ & $\begin{array}{l}\mathrm{Sq} \\
(\mu \mathrm{m})\end{array}$ & $\begin{array}{l}\mathrm{Sz} \\
(\mu \mathrm{m})\end{array}$ & $\begin{array}{l}\text { Sk } \\
(\mu \mathrm{m})\end{array}$ & $\begin{array}{l}\text { Sku } \\
(-)\end{array}$ & $\begin{array}{l}\text { Ssk } \\
(-)\end{array}$ & $\begin{array}{l}\text { Sdr } \\
(\%)\end{array}$ & & $\begin{array}{l}\mathrm{r}_{\mathrm{weq}} \\
(-)\end{array}$ \\
\hline PP0 & n.m. & n.m. & n.m. & n.m. & n.m. & n.m. & n.m. & n.m. & 1.00 \\
\hline PP1 & 0.06 & 0.09 & 1.36 & 0.19 & 5.20 & 0.02 & 0.30 & 1.004 & 1.21 \\
\hline PP2 & 0.10 & 0.14 & 1.75 & 0.26 & 7.17 & -1.15 & 0.51 & 1.005 & 1.56 \\
\hline PP3 & 0.63 & 0.78 & 4.71 & 2.12 & 2.52 & -0.08 & 2.38 & 1.025 & 1.61 \\
\hline PP4 & 1.15 & 1.40 & 8.61 & 3.85 & 2.46 & -0.19 & 7.12 & 1.071 & 2.08 \\
\hline PP5 & 3.57 & 4.95 & 31.81 & 8.57 & 3.68 & -0.08 & 157.20 & 1.728 & 3.47 \\
\hline PP6 & 3.40 & 4.30 & 25.65 & 9.50 & 3.13 & 0.18 & 58.36 & 1.390 & 2.93 \\
\hline PP7 & 2.84 & 3.40 & 25.56 & 7.84 & 4.08 & 0.81 & 39.44 & 1.261 & 2.92 \\
\hline PP8 & 2.37 & 2.91 & 22.31 & 5.99 & 4.25 & 0.95 & 23.88 & 1.192 & 2.52 \\
\hline
\end{tabular}

Notes: Sa - average height; Sq - root mean square height; Sz - maximum height; Sk - core roughness depth; Sku - kurtosis; Ssk - skewness; Sdr - developed interfacial area ratio; F - true to nominal area ratio; $r_{w e q}$ - equivalent Wenzel factor. 
FIGURES

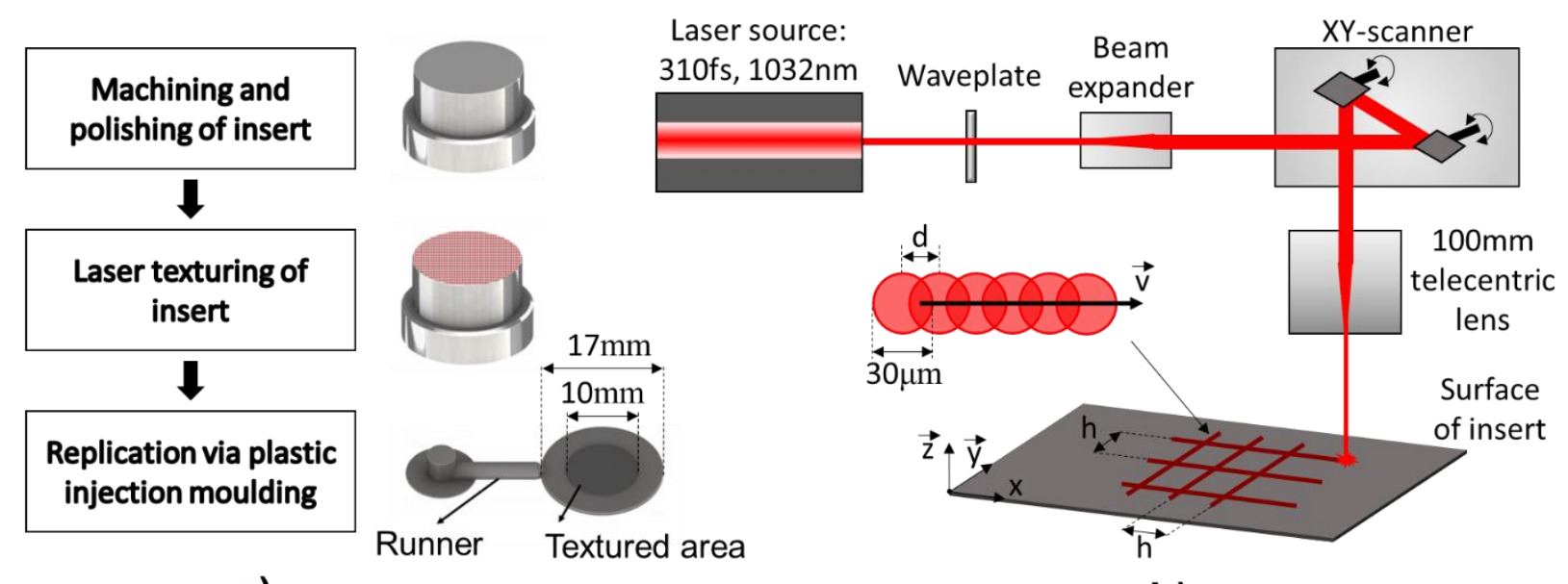

a)

b)

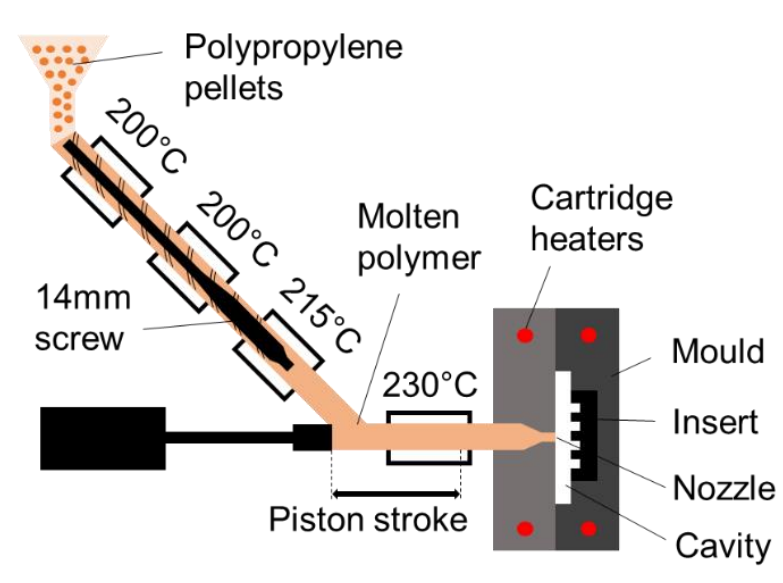

c)

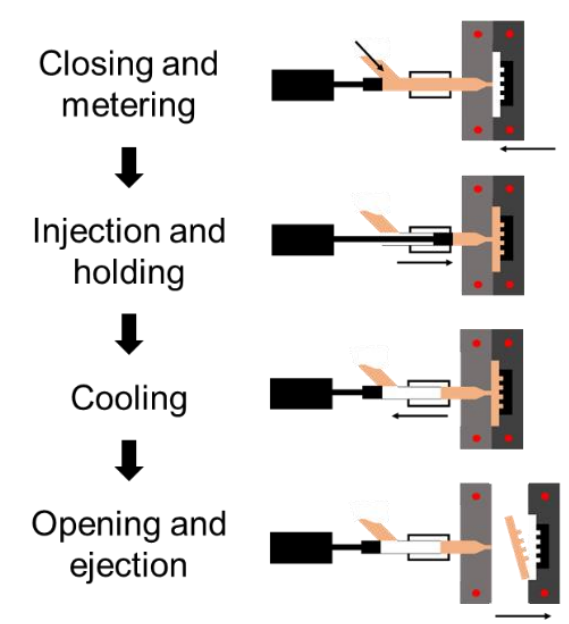

d)

Figure 1. The process chain used to produce polypropylene samples; a) the process steps included in the chain; b) the laser processing employed to texture the inserts where $\mathrm{d}$ and $\mathrm{h}$ refer to the pulse-to-pulse and hatch distance, respectively; c) replication of textured surfaces via injection moulding; d) the stages in the 25 s injection moulding cycle. 

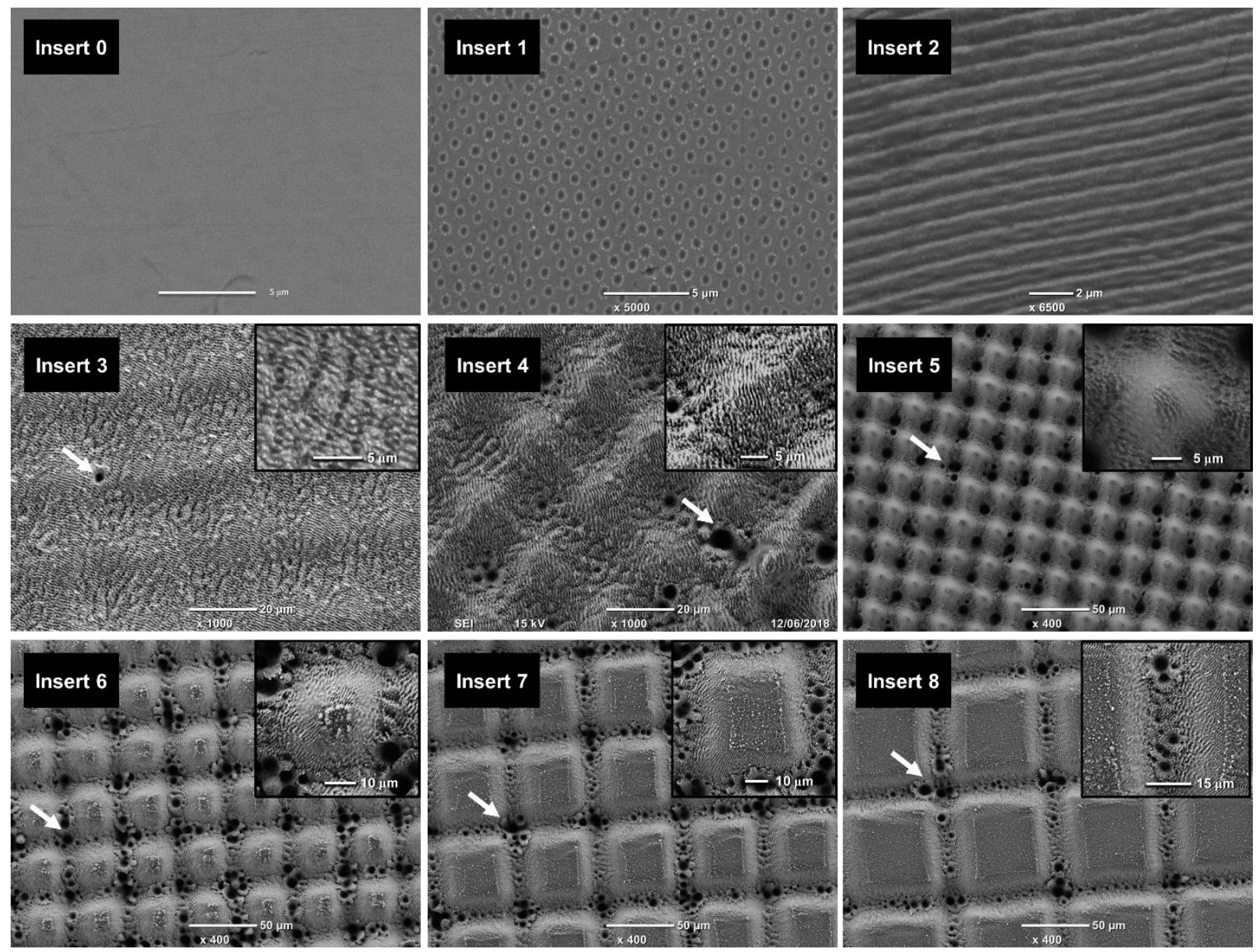

Figure 2. SEM images of laser-textured steel inserts where the white arrows point at sporadic holes. Topographical details are highlighted in close-up views. First row, from left to right: a polished surface, array of holes after $2.5-\mu \mathrm{J}$ laser irradiation, $1 \mathrm{D}$ grating generated with $900.7 \mu \mathrm{J}$ pulses. Middle row: laser processing with $7.9 \mu \mathrm{J} /$ pulse, $2 \mu \mathrm{m}$ pulse-to-pulse distance, $25 \mu \mathrm{m}$ pitch distance and 10, 20 and 50 pulses, respectively, from left to right. Bottom row: 20 scans at 7.9 $\mu \mathrm{J} /$ pulse, $1 \mu \mathrm{m}$ pulse-to-pulse distance and pitch distances of 40,60 and $80 \mu \mathrm{m}$, respectively, from left to right. 

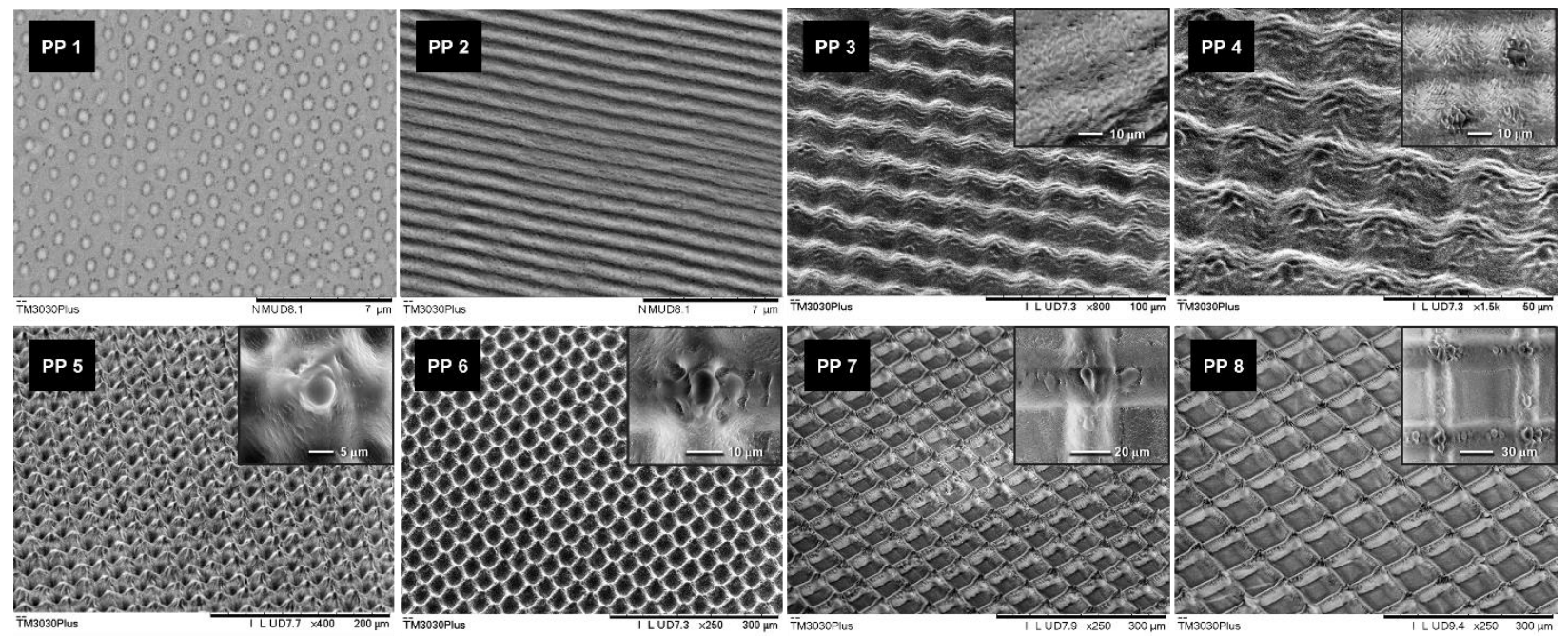

Figure 3. SEM images of micromoulded polypropylene surfaces. Topographical details are displayed in close-up views. PP1 to PP8 refer to the replica of laser-textured Inserts 1 to 8 , micromoulded with $200 \mathrm{~mm} / \mathrm{s}$ injection speed and 400 bars injection pressure. The mould temperature and holding pressure were $60^{\circ} \mathrm{C}$ and 450 bars for dual-scale topographies while $80^{\circ} \mathrm{C}$ and 700 bars for submicron topographies, respectively. Note: large views of PP3 to PP8 were viewed at $45^{\circ}$. 


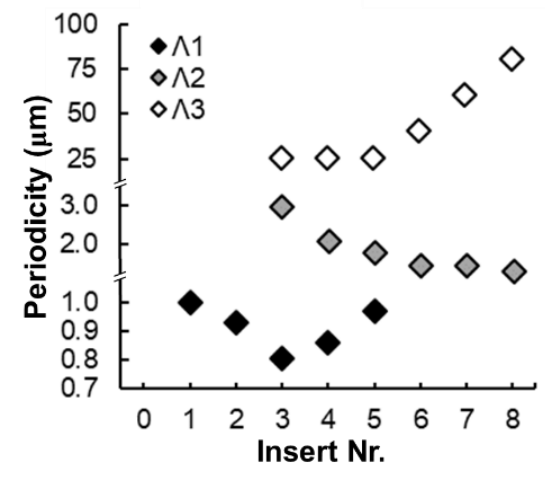

a)

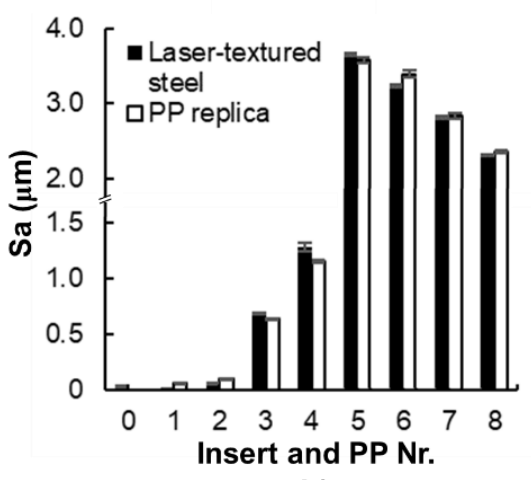

b)

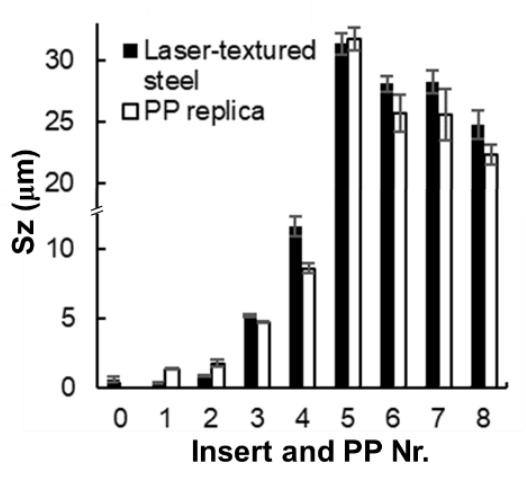

c)

Figure 4. Comparison of topographies on inserts and replicas: a) multiple periodicities of lasertextured topographies on the steel inserts; b) Sa of replicas and their respective inserts; c) Sz of replicas and their respective inserts. 


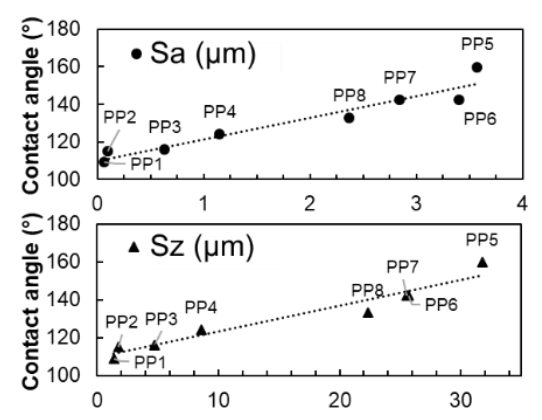

a)

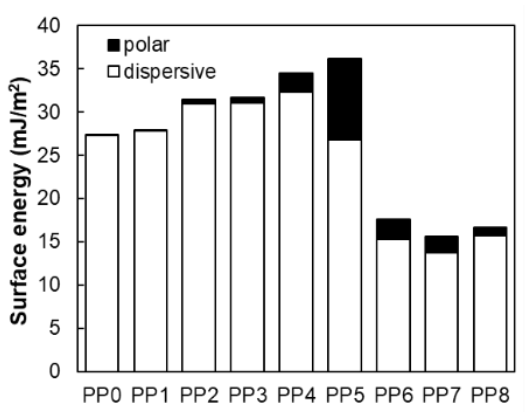

b)

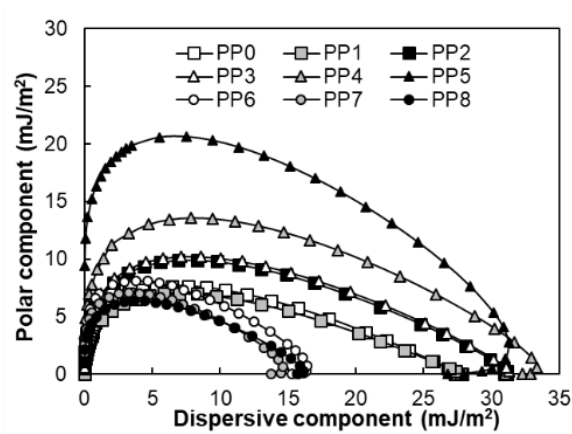

c)

Figure 5. The wetting properties of textured surfaces on micromoulded polypropylene samples:

a) the evolution of contact angle relative to $\mathrm{Sa}$ and $\mathrm{Sz}$; b) surface energy and c) wetting envelopes. 


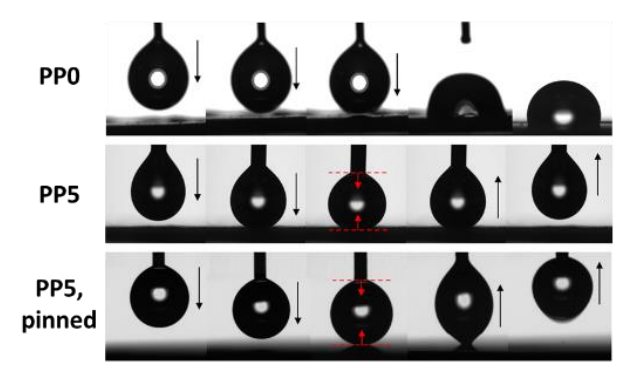

a)

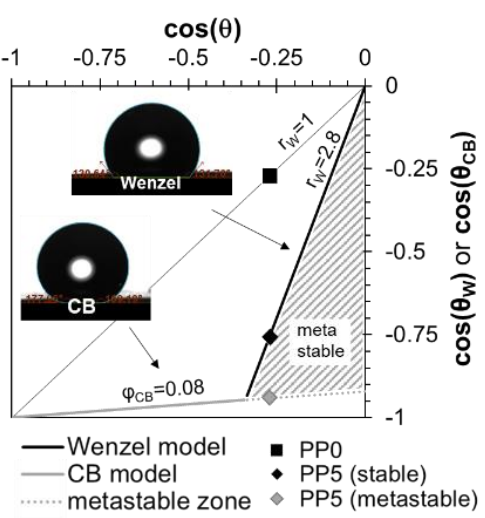

b)

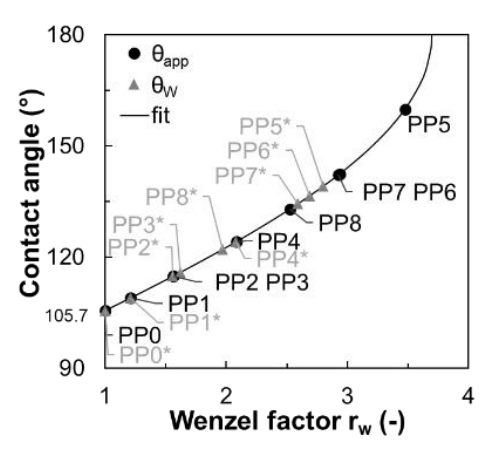

c)

Figure 6. Wettability analysis: a) deposition of a $6 \mu \mathrm{L}$ water drop on the untextured polymer compared to the PP5 one in Cassie-Baxter or Wenzel states, due to the exercised mechanical pressure; b) Wetting state transition for the PP5 sample; c) a comparison of apparent contact angle with the induced Wenzel state $(*)$ for the investigated topographies on the micromoulded samples. 


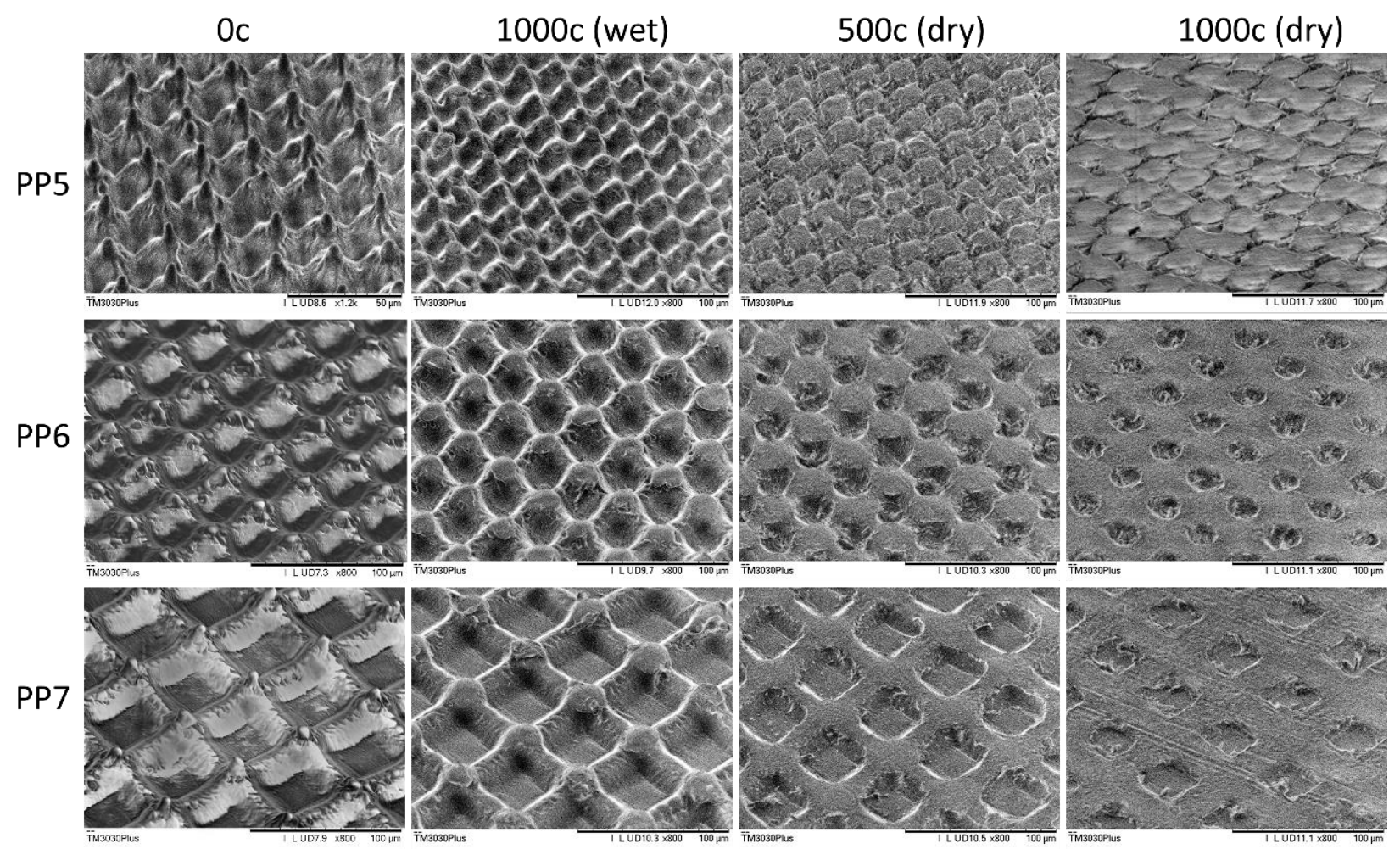

Figure 7. SEM images of textured surfaces on the PP5, PP6 and PP7 samples viewed at $45^{\circ}$ after cleaning cycles in wet and dry conditions. 


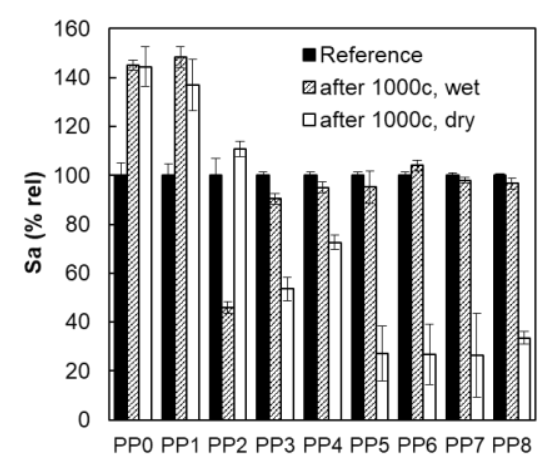

a)

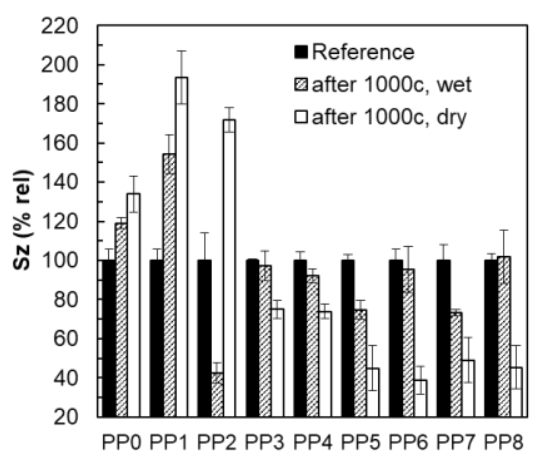

b)

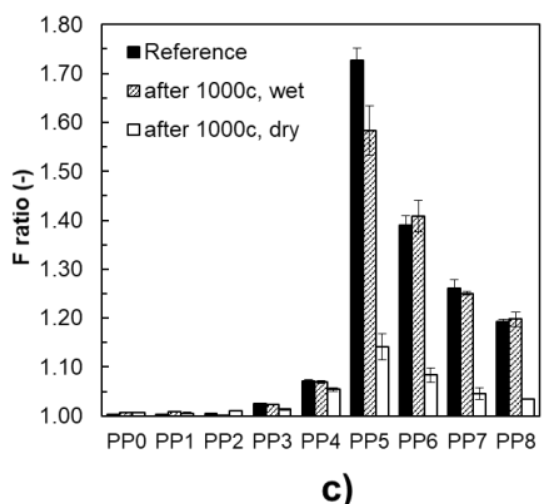

c)

Figure 8. The evolution of surface topographies on micromoulded polypropylene samples after 1000 cleaning cycles for: a) Sa; b) Sz; and c) F. 


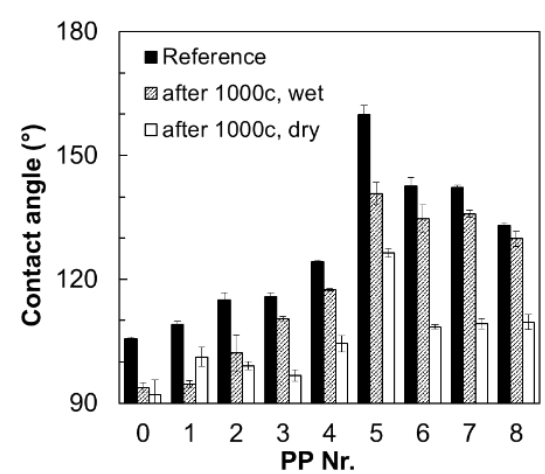

a)

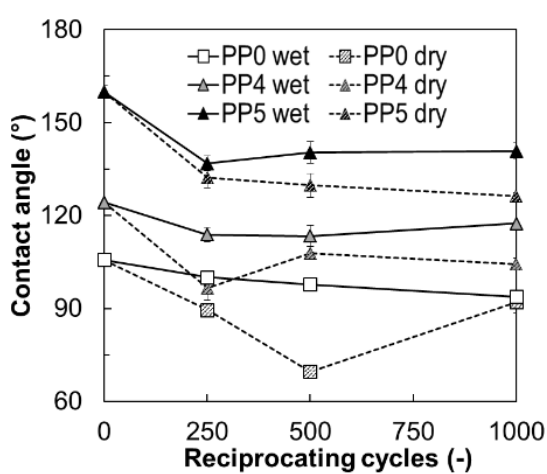

b)

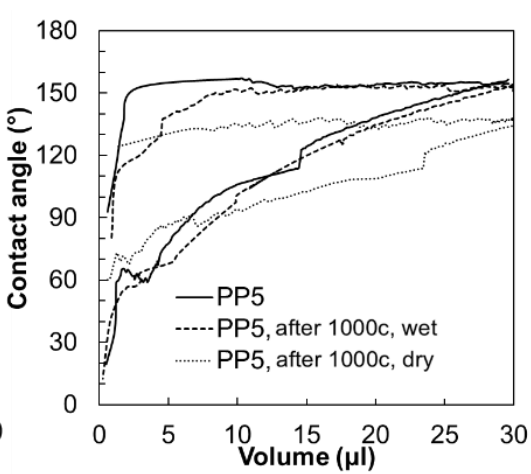

c)

Figure 9. The wettability evolution on micromoulded polypropylene surfaces after the abrasive cycles: a) water contact angles after 1000 cycles in wet and dry conditions; b) the evolution of contact angles on the PP0, PP4 and PP5 samples after 250, 500, 750 and 1000 cleaning cycles; and c) the advancing and receding contact angles of PP5 surfaces before and after 1000 wet and dry abrasion cycles. 

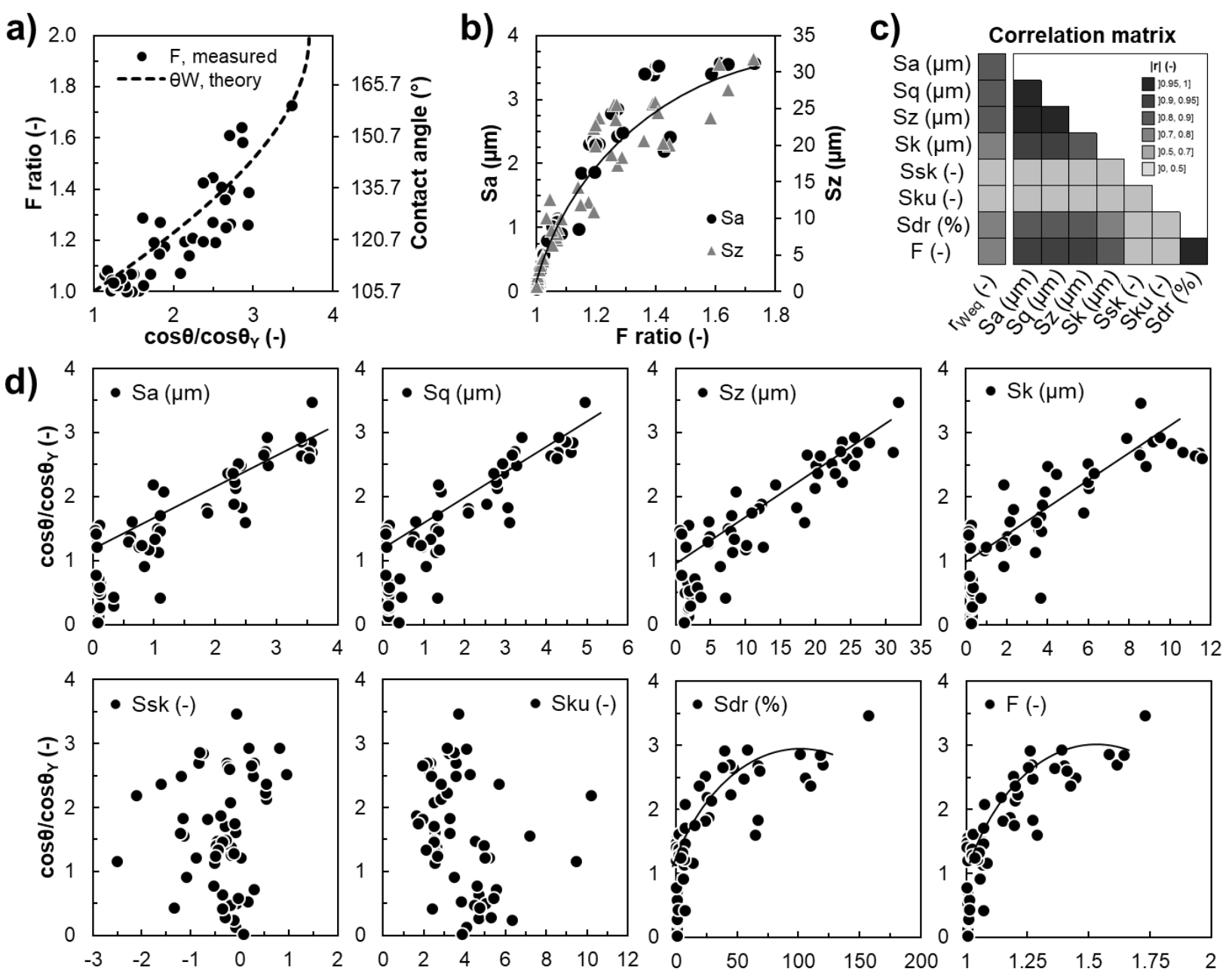

Figure 10. The interdependencies between 3D areal parameters and wettability: a) the interdependence between F and wettability; b) the relation between $\mathrm{Sa}, \mathrm{Sz}$ and F; c) the matrix of Pearson correlation coefficients; d) the scatter plot screeners for the 3D areal parameters of every investigated polypropylene topography in regard to normalised wettability. 


\section{ACKNOWLEDGMENT}

The research reported in this paper was carried out within the framework of European Commission H2020 ITN programme "European ESRs Network on Short Pulsed Laser Micro/Nanostructuring of Surfaces for Improved Functional Applications" (Laser4Fun) under the Marie Skłodowska-Curie grant agreement No. 675063 (www.laser4fun.eu) and the UKIERI DST programme "Surface functionalisation for food, packaging, and healthcare applications". In addition, the work was supported by three other H2020 programmes, i.e. the projects on "Modular laser based additive manufacturing platform for large scale industrial applications" (MAESTRO), "High-Impact Injection Moulding Platform for mass-production of 3D and/or large microstructured surfaces with Antimicrobial, Self-cleaning, Anti-scratch, Anti-squeak and Aesthetic functionalities" (HIMALAIA) and "Process Fingerprint for Zero-defect Net-shape Micromanufacturing" (MICROMAN). The authors would like also to acknowledge the support and assistance of Bosch Siemens Home Appliances (B/S/H/ Spain) in conducting this research. 


\section{REFERENCES}

[1] F. Völkermeyer, P. Jaeschke, U. Stute, D. Kracht, Laser-based modification of wettablility for carbon fiber reinforced plastics, Appl. Phys. A. 112 (2013) 179-183.

doi:10.1007/s00339-012-7237-3.

[2] M. Belhadjamor, M.E. Mansori, S. Belghith, S. Mezlini, Anti-fingerprint properties of engineering surfaces: a review, Surf. Eng. 34 (2018) 85-120. doi:10.1080/02670844.2016.1258449.

[3] B. Stoehr, C. Hall, D. Evans, P. Murphy, Cleaning Dirty Surfaces: A Three-Body Problem, ACS Appl. Mater. Interfaces. 8 (2016) 18534-18539. doi:10.1021/acsami.6b04181.

[4] T. Young, An essay on the cohesion of fluids, Philos. Trans. R. Soc. Lond. 95 (1805) 6587. doi:10.1098/rstl.1805.0005.

[5] D. Quéré, Wetting and Roughness, Annu. Rev. Mater. Res. 38 (2008) 71-99. doi:10.1146/annurev.matsci.38.060407.132434.

[6] K. Koch, B. Bhushan, Y.C. Jung, W. Barthlott, Fabrication of artificial Lotus leaves and significance of hierarchical structure for superhydrophobicity and low adhesion, Soft Matter. 5 (2009) 1386-1393. doi:10.1039/B818940D.

[7] A.-M. Kietzig, S.G. Hatzikiriakos, P. Englezos, Patterned Superhydrophobic Metallic Surfaces, Langmuir. 25 (2009) 4821-4827. doi:10.1021/la8037582.

[8] J. Long, P. Fan, D. Gong, D. Jiang, H. Zhang, L. Li, M. Zhong, Superhydrophobic Surfaces Fabricated by Femtosecond Laser with Tunable Water Adhesion: From Lotus Leaf to Rose Petal, ACS Appl. Mater. Interfaces. 7 (2015) 9858-9865. doi:10.1021/acsami.5b01870.

[9] A.-M. Kietzig, M.N. Mirvakili, S. Kamalb, P. Englezos, S.G. Hatzikiriakos, Nanopatterned Metallic Surfaces: Their Wettability and Impact on Ice Friction, J. Adhes. Sci. Technol. 25 (2011) 1293-1303. doi:10.1163/016942411X555872.

[10] M. Martínez-Calderon, A. Rodríguez, A. Dias-Ponte, M.C. Morant-Miñana, M. GómezAranzadi, S.M. Olaizola, Femtosecond laser fabrication of highly hydrophobic stainless steel surface with hierarchical structures fabricated by combining ordered microstructures and LIPSS, Appl. Surf. Sci. 374 (2016) 81-89. doi:10.1016/j.apsusc.2015.09.261.

[11] J.T. Cardoso, A. Garcia-Girón, J.M. Romano, D. Huerta-Murillo, R. Jagdheesh, M. Walker, S.S. Dimov, J.L. Ocaña, Influence of ambient conditions on the evolution of wettability properties of an IR-, ns-laser textured aluminium alloy, RSC Adv. 7 (2017) 39617-39627. doi:10.1039/C7RA07421B.

[12] P.O. Caffrey, B.K. Nayak, M.C. Gupta, Ultrafast laser-induced microstructure/nanostructure replication and optical properties, Appl. Opt. 51 (2012) 604609. doi:10.1364/AO.51.000604.

[13] B.K. Nayak, P.O. Caffrey, C.R. Speck, M.C. Gupta, Superhydrophobic surfaces by replication of micro/nano-structures fabricated by ultrafast-laser-microtexturing, Appl. Surf. Sci. 266 (2013) 27-32. doi:10.1016/j.apsusc.2012.11.052.

[14] S. Falah Toosi, S. Moradi, M. Ebrahimi, S.G. Hatzikiriakos, Microfabrication of polymeric surfaces with extreme wettability using hot embossing, Appl. Surf. Sci. 378 (2016) 426434. doi:10.1016/j.apsusc.2016.03.116.

[15] R.N. Wenzel, Resistance of solid surfaces to wetting by water, Ind. Eng. Chem. 28 (1936) 988-994. doi:10.1021/ie50320a024.

[16] A.B.D. Cassie, S. Baxter, Wettability of porous surfaces, Trans. Faraday Soc. 40 (1944) 546-551. doi:10.1039/TF9444000546. 
[17] A.-M. Kietzig, M.N. Mirvakili, S. Kamal, P. Englezos, S.G. Hatzikiriakos, Laser-Patterned Super-Hydrophobic Pure Metallic Substrates: Cassie to Wenzel Wetting Transitions, J. Adhes. Sci. Technol. 25 (2011) 2789-2809. doi:10.1163/016942410X549988.

[18] J. Han, M. Cai, Y. Lin, W. Liu, X. Luo, H. Zhang, K. Wang, M. Zhong, Comprehensively durable superhydrophobic metallic hierarchical surfaces via tunable micro-cone design to protect functional nanostructures, RSC Adv. 8 (2018) 6733-6744. doi:10.1039/C7RA13496G.

[19] D. Gong, J. Long, D. Jiang, P. Fan, H. Zhang, L. Li, M. Zhong, Robust and Stable Transparent Superhydrophobic Polydimethylsiloxane Films by Duplicating via a Femtosecond Laser-Ablated Template, ACS Appl. Mater. Interfaces. 8 (2016) 1751117518. doi:10.1021/acsami.6b03424.

[20] X. Bai, C.-H. Xue, S.-T. Jia, Surfaces with Sustainable Superhydrophobicity upon Mechanical Abrasion, ACS Appl. Mater. Interfaces. 8 (2016) 28171-28179. doi:10.1021/acsami.6b08672.

[21] N. Wang, D. Xiong, Y. Deng, Y. Shi, K. Wang, Mechanically Robust Superhydrophobic Steel Surface with Anti-Icing, UV-Durability, and Corrosion Resistance Properties, ACS Appl. Mater. Interfaces. 7 (2015) 6260-6272. doi:10.1021/acsami.5b00558.

[22] G.R.B.E. Römer, A.J. Huis in't Veld, J. Meijer, M.N.W. Groenendijk, On the formation of laser induced self-organizing nanostructures, CIRP Ann. - Manuf. Technol. 58 (2009) 201204. doi:10.1016/j.cirp.2009.03.068.

[23] A.Y. Vorobyev, C. Guo, Multifunctional surfaces produced by femtosecond laser pulses, J. Appl. Phys. 117 (2015) 033103. doi:10.1063/1.4905616.

[24] J.-M. Romano, A. Garcia-Giron, P. Penchev, S. Dimov, Triangular laser-induced submicron textures for functionalising stainless steel surfaces, Appl. Surf. Sci. 440C (2018) $162-169$.

[25] X. Sedao, T.J.-Y. Derrien, G.R.B.E. Romer, B. Pathiraj, A.J. Huis in 't Veld, Laser surface micro-/nano-structuring by a simple transportable micro-sphere lens array, J. Appl. Phys. 112 (2012) 103111. doi:10.1063/1.4767471.

[26] P.C. Vella, S.S. Dimov, E. Brousseau, B.R. Whiteside, A new process chain for producing bulk metallic glass replication masters with micro- and nano-scale features, Int. J. Adv. Manuf. Technol. 76 (2015) 523-543. doi:10.1007/s00170-014-6148-1.

[27] C.K. Huang, Polymeric nanofeatures of $100 \mathrm{~nm}$ using injection moulding for replication, J. Micromechanics Microengineering. 17 (2007) 1518. doi:10.1088/0960-1317/17/8/014.

[28] B. Sha, S. Dimov, C. Griffiths, M.S. Packianather, Micro-injection moulding: Factors affecting the achievable aspect ratios, Int. J. Adv. Manuf. Technol. 33 (2007) 147-156. doi:10.1007/s00170-006-0579-2.

[29] ASTM D3450-15, Standard Test Method for Washability Properties of Interior Architectural Coatings, ASTM Int., West Conshohocken, PA (2015). doi:10.1520/D345015.

[30] ISO 25178-2:2012, Geometrical product specifications (GPS); Surface texture: Areal; Part 2: Terms, definitions and surface texture parameters, Int. Org. Stand., Geneva (2012). www.iso.org/standard/42785.html.

[31] D.K. Owens, R.C. Wendt, Estimation of the surface free energy of polymers, J. Appl. Polym. Sci. 13 (1969) 1741-1747. doi:10.1002/app.1969.070130815. 
[32] C.J. Van Oss, L. Ju, M.K. Chaudhury, R.J. Good, Estimation of the polar parameters of the surface tension of liquids by contact angle measurements on gels, J. Colloid Interface Sci. 128 (1989) 313-319. doi:10.1016/0021-9797(89)90345-7.

[33] Jerry M. Fischer, Handbook of Molded Part Shrinkage and Warpage, William Andrew, 2003.

[34] L.-A. O'Hare, S. Leadley, B. Parbhoo, Surface physicochemistry of corona-dischargetreated polypropylene film, Surf. Interface Anal. 33 (2002) 335-342. doi:10.1002/sia.1217. 